\title{
A ATUAÇÃO DO COMITÊ PARALÍMPICO BRASILEIRO ENQUANTO ORGANIZAÇÃO DA SOCIEDADE CIVIL DE INTERESSE PÚBLICO
}

\author{
THE BRAZILIAN PARALYMPIC COMMITTEE AS A CIVIL SOCIETY \\ ORGANIZATION OF PUBLIC INTEREST \\ EL DESEMPEÑO DEL COMITÉ PARALÍMPICO BRASILEÑO COMO \\ ORGANIZACIÓN DE LA SOCIEDAD CIVIL DE INTERÉS PÚBLICO
}

Sabrina Furtado*, Nadyne Venturini Trindade* ${ }^{\star *}$ Fernando Marinho Mezzadri*

Palavras chave:

Esportes para

pessoas com

deficiência.

Organizações.

governamental.
Financiamento
Keywords:

Sports for persons

with disabilities.

Organizations.

Government funding
Resumo: Este artigo buscou verificar se o Comitê Paralímpico Brasileiro (CPB) atende aos princípios da legislação vigente no tocante à implementação de projetos de interesse social financiados com recursos públicos (2010-2016). Desde 2012, o CPB detém o título de Organização da Sociedade Civil de Interesse Público (OSCIP), o que prescreve a implementação de atividades de interesse público e rigor no processo de prestação de contas. Os dados provenientes dos relatórios de prestação de contas dos repasses adquiridos por meio dos Termos de Parceria e da Lei Agnelo/Piva foram contrastados à luz do Planejamento Estratégico e o Estatuto Social do CPB. Os resultados indicam aspectos conflitantes entre as especificações legais que regem a atuação das organizações de interesse público e as normativas do financiamento dos comitês esportivos nacionais.

Abstract: This study was intended to verify compliance by the Brazilian Paralympic Committee (BPC) with legal principles governing implementation of state-funded public interest projects (2010-2016). Since 2012, the BPC has been classified as a Civil Society Organization of Public Interest (OSCIP). Legislation requires such organizations to implement social interest activities and follow rigorous accountability processes. Data from BPC's accountability reports and funding records for Partnership Terms and the so-called Agnelo/Piva Law were contrasted in light of BPC's Strategic Planning and Bylaws. The results point to conflicts between legal standards governing activities of organizations of public interest and the rules on funding national sports committees.

Palabras clave: Deportes para personas con discapacidad. Organizaciones. Financiación gubernamental.
Resumen: Este artículo tuvo como objetivo verificar si el Comité Paralímpico Brasileño (CPB) cumple con los principios de la legislación vigente en lo que se refiere a la implementación de proyectos de interés social financiados con fondos públicos (20102016). Desde 2012, el CPB ha ostentado el título de Organización de la Sociedad Civil de Interés Público (OSCIP), lo que prescribe la implementación de actividades de interés público y rigor en el proceso de rendición de cuentas. Los datos de informes de rendición de cuentas de los fondos obtenidos a través de Términos de Colaboración y de la Ley Agnelo/Piva se contrastaron a la luz de la Planificación Estratégica y del Estatuto Social del CPB. Los resultados indican aspectos contradictorios entre las especificaciones legales que rigen las actividades de las organizaciones de interés público y las normas de financiación de los comités deportivos nacionales.
*Universidade Federal do Paraná. Curitiba, PR, Brasil. E-mail: sabrina_mfurtado@ @otmail.com; mezzadri@ufpr.com.br

${ }^{*}$ School of Sport, Exercise and Health Sciences. Universidade de Loughborough. Loughborough, Leicestershire. Reino Unido. E-mail: nadynetrindade@gmail.com

Recebido em: 26-04-2019 Aprovado em: 27-09-2019 Publicado em: 10-12-2019

DOI https://doi.org/10.22456/1982-8918.92201 (c) (1) (8) Licence cc) (1) () Creative Commom 


\section{INTRODUÇÃO}

As instituições do Terceiro Setor ${ }^{1}$ exercem um papel expressivo na provisão de programas esportivos no país (MELO, 2017; TRINDADE, 2017). A disseminação dessas instituições e 0 papel suplementar frente às demandas não contempladas pela iniciativa pública têm relevância no contexto de austeridade no financiamento de políticas para o esporte e o lazer. A atuação das organizações não governamentais (ONGs) se dá por meio de programas próprios e/ou em parcerias público-privadas, como no caso do Programa de Esporte e Lazer na Cidade (PELC), maior programa federal na área de esporte e lazer comunitário (FIGUERÔA et al., 2014).

O papel gerencial assumido pelo Estado e o favorecimento dos interesses econômicos em parcerias estabelecidas com a iniciativa privada para a promoção do esporte e da atividade física é amplamente discutido na literatura nacional e internacional (MELO, 2007; HOWARD; CROMPTON, 2018; LEE et al., 2018; LEGG; JONES; WHITE, 2018). No entanto, no campo acadêmico da Educação Física brasileira, as parcerias entre as ONGs, e mais especificamente entre as Organizações da Sociedade Civil de Interesse Público (OSCIPs) e o poder público foram pouco exploradas.

A qualificação de uma ONG como OSCIP foi regulamentada no país por meio da Lei 9.790/1999. Ferrarezi e Rezende (2005) apontam que a criação da lei teve por objetivo garantir a especificação e a diferenciação das atividades de organizações do terceiro setor, destacando a atuação na produção de bens e serviços de caráter público. Dentre outras especificações, essa legislação determina que as organizações intituladas tenham objetivos sociais e normas estatutárias regidas pelos princípios da universalização dos serviços e da promoção de direitos sociais (BRASIL, 1999). Para Lahoz e Duarte (2015), este princípio pressupõe que as ONGs qualificadas ofereçam bens e serviços a todos os cidadãos de forma igualitária, sem distinção ou privilégio de uns em detrimento de outros.

Dentre as instituições esportivas brasileiras qualificadas como OSCIPs, o Comitê Paralímpico Brasileiro (CPB) destaca-se pelos resultados esportivos em Jogos Paralímpicos (JP), Campeonatos Mundiais e Jogos Parapan-americanos. Também recebe reconhecimento internacional pela sua gestão, justificado pelas consultorias e intercâmbios com países que buscam promover o Movimento Paralímpico (COMITÊ PARALÍMPICO BRASILEIRO, 2017).

Os estudos de Reis (2014), Miranda (2011), Marques et al. (2009) tratam de ações estratégicas desenvolvidas pelo Comitê nos últimos vinte anos e das especificidades do desporto paralímpico no país. Entretanto, apesar do título de OSCIP, não existem referências sobre as ações de responsabilidade legal e social do CPB no desenvolvimento do esporte paralímpico a nível nacional. Assim, faz-se necessário analisar as ações desenvolvidas pelo CPB em prol do desenvolvimento do esporte paralímpico em face da legislação concernente, a fim de compreender como esta instituição se liga ao Estado e às demais entidades administrativas do esporte.

Este estudo busca endereçar essa lacuna a partir de uma análise documental qualitativa sobre o financiamento da principal entidade administradora do esporte paralímpico brasileiro. O objetivo desta pesquisa foi verificar se o CPB, enquanto OSCIP, atende aos princípios da legislação vigente no tocante à implementação de atividades de interesse público. Para isso, foram analisados os projetos de intervenção do CPB financiados com recursos públicos entre os anos de 2010 e 2016, confrontando-os a partir das especificações legais que definem a atuação das organizações de interesse público e das organizações esportivas.

1 Ao longo do texto, os termos ONG e organizaç̃es esportivas "do terceiro setor", "sem fins lucrativos", "não governamentais", "da sociedade civil" são utilizados como equivalentes tendo como critério agrupador a oferta de "[...] ações institucionalizadas, privadas, não distribuidoras de lucro, autoadministradas e voluntárias" (IBGE, 2012, p. 14). 
Os dados financeiros do CPB foram extraídos dos balanços financeiros da instituição, dos anos de 2010 a 2016, consultados no seu site, através do link “FINANCEIRO"2. A publicação deste tipo de documento é obrigatória a todas as instituições esportivas que recebem recursos públicos, devendo ser auditado de forma independente da instituição (BRASIL, 1998). 0 recorte temporal da pesquisa se deu em razão do Planejamento Estratégico do CPB, que foi delineado para o período proposto. 0 planejamento estratégico de uma instituição é a base para a execução de seus projetos e programas, e, portanto, a análise se deu de acordo com a efetivação das ações previstas. Por meio da consulta aos balanços financeiros verificamos 0 volume de recursos arrecadados por fonte de financiamento por ano. Outra informação que foi possível extrair desses documentos foi o valor da despesa executada pelo CPB para as áreas especificadas através da Lei 9.615/1998, que são o fomento, a formação de recursos humanos, a preparação técnica e a participação de atletas em eventos esportivos. Os dados referentes aos convênios firmados com o Ministério do Esporte ${ }^{3}(\mathrm{ME})$ foram consultados através do "Portal da Transparência"4 do governo federal, por meio da busca "Transferência de Recursos". As buscas foram realizadas utilizando-se o nome do convenente ("Comitê Paralímpico Brasileiro") e o número do CNPJ do órgão, para cada um dos anos do recorte temporal desta análise. Através do Portal da Transparência, foi possível acessar o "Sistema de Convênios do Governo Federal"5 (SICONV), onde os convênios firmados entre o CPB e o ME puderam ser acessados na íntegra, o que possibilitou a consulta aos objetivos dos convênios firmados, bem como 0 público-alvo dos respectivos projetos e o volume de recursos previstos e liquidados para cada um dos convênios.

Os dados coletados foram inseridos e organizados em planilhas, utilizando o software Excel (versão Office 2007). A tabulação dos dados discriminou o volume de recursos recebidos por fonte e por ano. Posteriormente estes dados foram catalogados em um gráfico. Os valores monetários foram deflacionados por meio do índice de preços do Banco Central do Brasil ${ }^{6}$ (BCB), com base no ano de 2019. Para análise dos projetos previstos e executados pelo CPB para o período analisado, examinamos o Planejamento Estratégico 2010-2016, disponibilizado no sítio eletrônico da organização, notícias veiculadas nas redes sociais da instituição e relatórios publicados durante o período analisado, nas edições da revista "Brasil Paraolímpico". A fim de verificar a efetivação e execução dos projetos previstos pelo CBP, três colaboradores da instituição foram contatados. Destes colaboradores, um era ligado ao departamento técnico, outro ao departamento de eventos e outro do departamento de comunicação do Comitê. 0 contato inicial com os colabores se deu via email, e posteriormente por meio visitas a eventos organizados pela instituição, bem como por telefone. Os colabores da instituição confirmaram a efetivação dos projetos beneficiados, o objetivo finalístico e o público-alvo.

Para este estudo, a análise foi dividida em três partes. A primeira delas trata das especificidades do terceiro setor brasileiro. Na segunda parte discute-se a estrutura administrativa, o financiamento e os projetos desenvolvidos pelo CPB. Por último, a atuação do CPB enquanto OSCIP é discutida à luz das atividades de interesse público.

\footnotetext{
2 Disponível em: http://gestaorecursos.cpb.org.br/outras.php. Acesso em: 18 out. 2019.

30 Ministério do Esporte foi extinto em 2019 inicialmente pela Medida provisória 870/2019, convertida posteriormente na Lei n 13.844/2019, sendo o órgão responsável pela gestão do esporte a nível nacional a partir de então, a Secretaria Especial do Esporte.

4 Disponível em: http://www.portaltransparencia.gov.br/transferencias/consulta?ordenarPor=mesAno\&direcao=desc. Acesso em: 18 out. 2019. 5 Disponível em: https://voluntarias.plataformamaisbrasil.gov.br/voluntarias/proposta/ConsultarProposta/ConsultarProposta.do. Acesso em: 18 out. 2019. 


\section{OUTRO SETOR: A ESTRUTURAÇÃO DO TERCEIRO SETOR BRASILEIRO}

O desenvolvimento do nonprofit sector (setor sem fins lucrativos) se dá nos Estados Unidos no final dos anos de 1970 (HALL, 1994). O associativismo civil e o voluntariado constituíram-se como as bases para o desenvolvimento de uma proposta de atuação paralela aos setores público e privado. No Brasil, o terceiro setor se estruturou de forma alternativa, em significativa dependência dos outros setores (MELO, 2007; LANDIM, 1996; LINHALES, 1996).

No final da década de 1990, período de franca expansão das organizações sem fins lucrativos no Brasil, o conceito do terceiro setor passou a ser problematizado, uma vez que 0 termo dissolve as significativas diferenças entre organizações sociais comunitárias, entidades filantrópicas e os institutos empresariais (HADDAD, 2002). A relação dessas organizações com o Estado brasileiro é interpretada em sua complexidade e ambivalência pois, apesar de indispensável, é instável durante as trocas de gestão e a reorganização do orçamento público (LIMA NETO, 2013).

O ordenamento legal do terceiro setor visou responder à necessidade de categorizar as entidades sem fins lucrativos de forma mais precisa e de diversificar as oportunidades de financiamento. A legislação brasileira reconhece a Declaração de Utilidade Pública; 0 Certificado de Entidade de Fins Filantrópicos (CEFF); a Qualificação como Organização Social (OS); a Qualificação de Cooperativa Social e Qualificação de Organização da Sociedade Civil de Interesse Público (OSCIP) (DIAS, 2008). Tais títulos permitem o usufruto de subsídios, isenções fiscais e contribuições do Estado que, em contrapartida, regula o processo de prestação de contas e a adesão a regimes de trabalho específicos.

A regulamentação da concessão do título de OSCIP está condicionada à "execução direta de projetos, programas, planos de ações correlatas, por meio da doação de recursos físicos, humanos e financeiros" e/ou por meio da "prestação de serviços intermediários de apoio a outras organizações sem fins lucrativos e a órgãos do setor público que atuem em áreas afins" (BRASIL, 1999, p.1).

Além de tipificar as ONGs, a Lei das OSCIPs garante a formalização das atividades do terceiro setor nas decisões públicas por meio do Termo de Parceria, viabilizando o financiamento para a execução os serviços públicos sociais não exclusivos e a movimentação de recursos em direção ao desenvolvimento social (FERRAREZI, 2001b; 2001a; KOGA, 2004). Todavia, esses objetivos são paradoxais, pois podem ser interpretados tanto à guisa dos interesses das organizações pautadas na perspectiva de Estado mínimo quanto em relação aos interesses de entidades que visam ao acesso universal aos direitos sociais.

Dentre os resultados da regulamentação do terceiro setor, destaca-se o processo de profissionalização, a importação da visão de mercado e a incorporação dos aspectos de Governança Corporativa (GC) ${ }^{7}$ (ROCHA; FEITOSA, 2013). Essa reformulação legal favorece as organizações altamente pragmáticas, devido à capacidade técnica que detêm para atenderem às demandas gerenciais do financiamento público ao mesmo tempo que usufruem da autonomia atribuída pelo regime jurídico (THIESENA, 2009).

No universo das políticas públicas de caráter social, o esporte ocupa um espaço marginal (LINHALES, 1996; SILVA; ROMERA; BORGES, 2014). Apesar da legislação esportiva conceber a priorização das atividades de caráter educacional, a maior parcela da distribuição

7 As chamadas boas práticas de Governança Corporativa referem-se às tentativas de alinhamento dos interesses dos gestores e dos financiadores com a finalidade de reorganizar e otimizar a estrutura administrativa e financeira, inspirando confiabilidade na organização e, com isso, atraindo maiores investimentos. (ROCHA; FEITOSA, 2013). 
de recursos públicos federais é direcionada à esfera do esporte de alto rendimento (BUENO, 2008). Assim como as atividades de promoção do esporte de elite, a atuação complementar do terceiro setor na área do esporte e do lazer segue a tendência de dependência do financiamento público (CORREIA, 2014), com destaque para a multiplicação de projetos sociais esportivos que priorizam o desenvolvimento de atividades competitivas e promoção do esporte de alto rendimento (CARAVAGE; OLIVER, 2018).

\section{O FINANCIAMENTO DO COMITÊ PARALÍMPICO BRASILEIRO}

O CPB foi fundado no ano de 1995, dois anos após a solicitação feita pelo International Paralympic Committee (IPC) para a criação de comitês nacionais de representação do Movimento Paralímpico (MIRANDA, 2011). O CPB estatutariamente é uma "organização civil de interesse público, sem fins lucrativos, com atuação em todo território nacional, reconhecida pela Legislação Desportiva Brasileira como entidade matriz do segmento esportivo paraolímpico8" (COMITÊ PARALÍMPICO BRASILEIRO, 2011).

O estatuto da instituição explicita ainda que a finalidade do órgão é a de representar, coordenar e dirigir o segmento esportivo paralímpico brasileiro nos níveis nacional e internacional, e está alinhada com o que propõe o IPC. A subordinação ao IPC, instituição máxima do esporte paralímpico, determina que os comitês nacionais a ele filiados contribuam para o desenvolvimento do movimento paralímpico, viabilizando que atletas paralímpicos alcancem excelência esportiva (INTERNATIONAL PARALYMPIC COMMITTEE, 2003).

A Lei Pelé (Lei no 9.615/1998) (BRASIL, 1998) determinou a inclusão da entidade no Sistema Nacional de Desporto (SND), concedendo ao CPB os direitos e benefícios conferidos às demais entidades nacionais de administração do desporto. Desde a sua promulgação, 0 CPB é a instituição responsável por elaborar e executar as atividades referentes ao esporte paralímpico e aos subsistemas específicos ${ }^{9}$ a este no Brasil. Além disso, o artigo 910, o qual previa a destinação anual da renda líquida total de um dos testes da Loteria Esportiva Federal para treinamento e preparação de equipes paralímpicas nacionais, garantiu inicialmente 0 repasse de recursos públicos ao CPB (BRASIL, 1998).

Em 2001, a aprovação da Lei Agnelo/ Piva (Lei no 10.264/2001) (BRASIL, 2001) trouxe inserções no artigo 56을 da Lei Pelé, determinando que $2 \%$ da arrecadação bruta dos concursos de prognósticos e loterias federais e similares passariam a ser destinados às entidades de organização do desporto nacional. Deste total, 15\% eram destinados anualmente ao CPB. Desde 2015, com a criação do Estatuto da Pessoa com Deficiência (Lei n- 13.146/2015) (BRASIL 2015), o valor do repasse aos comitês passou de $2 \%$ para 2,7\%, ampliando de $15 \%$ para $37,04 \%$ a remessa destinada ao CPB. Com a mudança, a receita da instituição cresceu de forma significativa, aumentando os recursos advindos da Lei Agnelo/Piva de $\mathrm{R} \$$ 54 milhões em 2015 para $\mathrm{R} \$ 130$ milhões em 2016. Dos recursos via Lei Agnelo/Piva, 10\% destinam-se ao desporto educacional e $5 \%$ ao desporto universitário, obrigatoriamente. Os $85 \%$ restantes podem ser dedicados às demais atividades de desenvolvimento do esporte, recursos humanos, locomoção participação de atletas em eventos esportivos (BRASIL, 2001).

8 Em 2011 houve uma mudança na grafia da palavra "paraolímpico" para "paralímpico", buscando padronizá-la mundialmente, dessa forma a letra "o" foi suprimida (MELLO; WINCKLER, 2012).

9 São consideradas instituições componentes do subsistema do esporte paralímpico brasileiro as entidades filiadas ou vinculadas ao CPB (associações, federações, confederações, ligas).

10 O artigo 9º da Lei 9.615/1998, teve sua vigência encerrada em outubro de 2018. 
Além do acesso direto a tais recursos, o CPB pode ainda captar financiamento via patrocínios, convênios firmados com o Estado e através da Lei do Incentivo ao Esporte.

Gráfico 1 - Especificação das fontes de financiamento do Comitê Paralímpico Brasileiro (2010-2016), com valores superiores a $\mathrm{R} \$ 4$ milhões

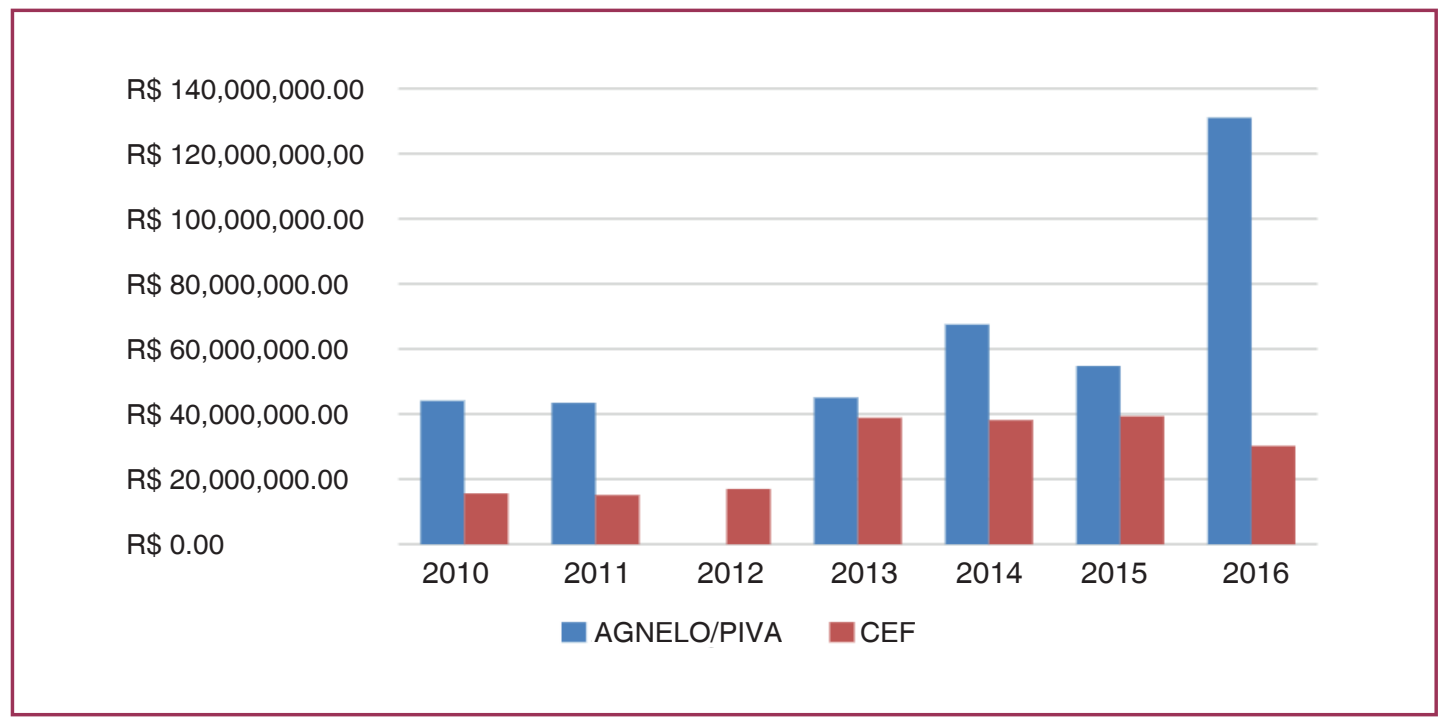

Fonte: autores, 2019.

Gráfico 2 - Especificação das fontes de financiamento do Comitê Paralímpico Brasileiro (2010-2016), com valores inferiores a $\mathrm{R} \$ 4$ milhões.

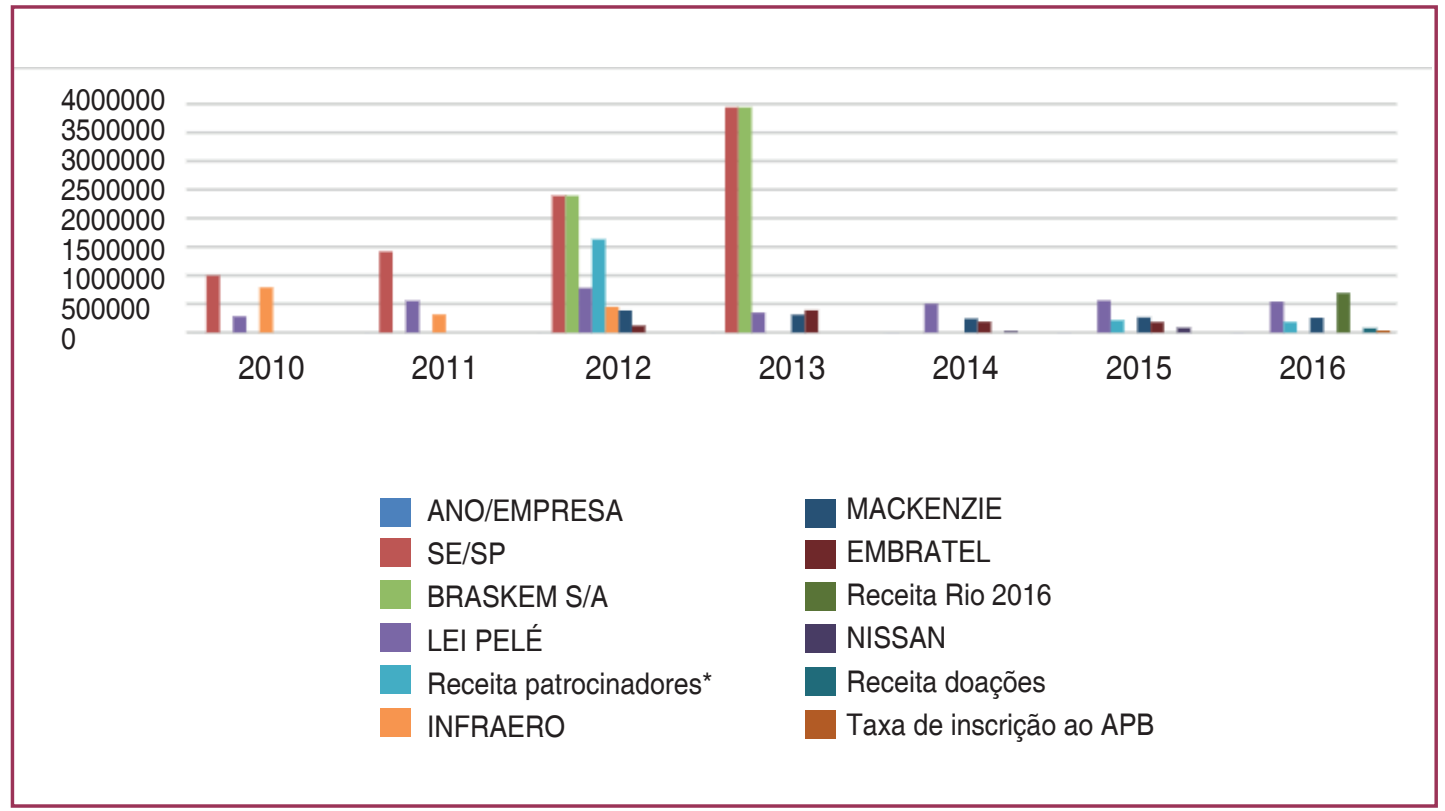

Fonte: autores, 2019

Conforme os gráficos 1 e 2, as fontes de recursos revelam a dependência dos recursos federais. Os dados corroboram a análise de Marques e Gutierrez (2014), que aponta que a sustentabilidade financeira do sistema paralímpico no Brasil provém dos recursos públicos, apesar do aumento no número de patrocinadores privados.

Com o título de OSCIP, o CPB goza da elegibilidade e simplificação na captação de recursos públicos adicionais por meio da celebração de Termo de Parceria com o Estado. Entre 2010 e 2015, 16 Termos de Parceria foram firmados com o Ministério de Esporte através 
da Secretaria Nacional de Esporte de Alto Rendimento (SNEAR), totalizando R 75 milhões ${ }^{11}$. No que se refere aos objetivos dos projetos financiados, oito destinavam-se à preparação de Seleções Paralímpicas Permanentes. Dois convênios referiam-se à participação da delegação brasileira em Jogos Parapan-Americanos de 2011 e 2015. Três projetos dedicaram-se com a realização de campeonatos de Basquetebol em Cadeira de Rodas e a identificação de novos talentos para a modalidade. Os três outros convênios objetivaram a aclimatação da delegação brasileira em Manchester antes dos Jogos Paralímpicos de Londres 2012, 0 intercâmbio internacional de treinamento de seleções de diferentes modalidades e a contratação de profissionais para equipes multidisciplinares das 12 modalidades contempladas pelo Plano Brasil Medalha 2016/Programa Bolsa Pódio.

Tabela 1 - Termos de Parceria firmados entre o CPB e ME entre os anos de 2010 e 2016

\begin{tabular}{|c|c|c|c|c|}
\hline № & Início & Fim & Programa & $\begin{array}{c}\text { Valor } \\
\text { liberado R\$ }\end{array}$ \\
\hline 1 & 12. 2015 & 12. 2016 & $\begin{array}{c}\text { Preparação e Organização dos Jogos Olímpicos e Paralímpico } \\
\text { (Plano Brasil Medalhas 2016) Rio } 2016\end{array}$ & $5.063 .461,301$ \\
\hline 2 & 12. 2014 & 10. 2015 & $\begin{array}{c}\text { Preparação e Organização dos Jogos Olímpicos } \\
\text { e Paralímpicos Rio } 2016\end{array}$ & $2.370 .519,480$ \\
\hline 3 & 12. 2013 & 11. 2014 & $\begin{array}{c}\text { Preparação de atletas e Capacitação de Recursos Humanos } \\
\text { Esporte de Alto Rendimento. }\end{array}$ & $793.827,18$ \\
\hline 4 & 12. 2013 & 05.2014 & $\begin{array}{l}\text { Preparação de atletas e Capacitação de Recursos Humanos } \\
\text { para o Esporte de Alto Rendimento. }\end{array}$ & $1.259 .808,68$ \\
\hline 5 & 12. 2012 & 08. 2016 & $\begin{array}{c}\text { Preparação e Organização dos Jogos Olímpicos } \\
\text { e Paralímpicos Rio } 2016\end{array}$ & $36.416 .908,46$ \\
\hline 6 & 10. 2012 & 06.2013 & Preparação de Atletas & $1.645 .316,94$ \\
\hline 7 & 12. 2011 & 04.2013 & $\begin{array}{c}\text { Preparação e Organização dos Jogos Olímpicos } \\
\text { e Paralímpicos Rio } 2016\end{array}$ & $11.921 .571,34$ \\
\hline 8 & 12. 2011 & 02. 2013 & $\begin{array}{c}\text { Preparação e Organização dos Jogos Olímpicos } \\
\text { e Paralímpicos Rio } 2016\end{array}$ & $4.801 .305,25$ \\
\hline 9 & 08. 2011 & 05.2012 & $\begin{array}{c}\text { Preparação e Organização dos Jogos Olímpicos } \\
\text { e Paralímpicos Rio } 2016\end{array}$ & $1.310 .713,27$ \\
\hline 10 & 12. 2010 & 05.2012 & $\begin{array}{c}\text { SNEAR Rio 2016- Preparação e Organização dos Jogos } \\
\text { Olímpicos e Paralímpicos }\end{array}$ & $1.211 .798,10$ \\
\hline 11 & 12. 2010 & 05. 2012 & $\begin{array}{c}\text { SNEAR Paralímpicos Rio } 2016 \text { - Apoio a implantação de } \\
\text { infraestrutura para os Jogos Olímpicos e }\end{array}$ & $637.772,02$ \\
\hline 12 & 12. 2010 & 04. 2012 & $\begin{array}{c}\text { SNEAR Rio 2016- Preparação e Organização dos Jogos } \\
\text { Olímpicos e Paralímpicos }\end{array}$ & $310.068,09$ \\
\hline 13 & 12. 2010 & 07.2012 & $\begin{array}{c}\text { SNEAR Rio 2016- Preparação e Organização dos Jogos } \\
\text { Olímpicos e Paralímpicos }\end{array}$ & $2.012 .529,24$ \\
\hline 14 & 12. 2010 & 08. 2012 & $\begin{array}{c}\text { SNEAR Rio 2016- Preparação e Organização dos Jogos } \\
\text { Olímpicos e Paralímpicos }\end{array}$ & $1.081 .473,77$ \\
\hline 15 & 12. 2010 & 03. 2012 & $\begin{array}{c}\text { SNEAR Rio 2016- Preparação e Organização dos Jogos } \\
\text { Olímpicos e Paralímpicos }\end{array}$ & $2.105 .003,58$ \\
\hline 16 & 12. 2010 & 12. 2012 & $\begin{array}{c}\text { SNEAR Rio 2016- Preparação e Organização dos Jogos } \\
\text { Olímpicos e Paralímpicos }\end{array}$ & $2.126 .935,97$ \\
\hline
\end{tabular}

Fonte: Os autores, 2019.

11 Os convênios entre o CPB e o ME foram consultados no Portal da Transparência do Governo Federal. Disponível em: http://transparencia gov.brl. Acesso em: 3 abr. 2016. 
O Planejamento Estratégico (PE) da instituição para o período de 2010 a 2016 apresenta como missão institucional: 1) "Promover o desenvolvimento dos diversos esportes paralímpicos no Brasil, em articulação com as respectivas organizações nacionais", 2) "Promover a universalização do acesso das pessoas com deficiência à prática esportiva em seus diversos níveis", e 3) "Organizar a participação do Brasil em competições continentais, mundiais e Jogos Paralímpicos sempre na busca da excelência da performance esportiva" (COMITÊ PARALÍMPICO BRASILEIRO, 2009, p.8).

Doze dos 18 programas propostos no PE para o período foram implementados com 0 uso dos recursos da Lei Agnelo/Piva. Entre estes, dez correspondem aos eixos 1 e 3 . Tais programas desenvolveram ações relativas ao treinamento de atletas classificados pelo CPB e pelas respectivas confederações esportivas pelo potencial de ganhar medalhas nos JP de Londres 2012 e do Rio 2016. Entre estes, destacam-se o Projeto Ouro, o Time São Paulo ou Time Rio e as Seleções Paralímpicas Permanentes. Todos os programas acompanharam os indicadores internacionais de desempenho esportivo em competições internacionais (GREEN; OAKLEY, 2001; GREEN; HOULIHAN, 2005; BOSSCHER et al., 2006; BOSSCHER et al., 2009; HOULIHAN; ZHENG, 2013).

No tocante ao segundo eixo de atuação, o CPB conduziu um programa que foi desdobrado em dois projetos na área de desenvolvimento esportivo: as Paralimpíadas Escolares, que foram realizadas anualmente durante todo o período analisado. E o segundo projeto, o Clube Escolar Paralímpico, que foi executado apenas entre 2010 e 2012. Estes projetos foram implementados com os $10 \%$ do total de recursos repassados ao CPB via Lei Agnelo/Piva, que por força de Lei devem ser utilizados obrigatoriamente com o esporte escolar. Os outros dois programas previstos para a área de desenvolvimento do esporte escolar não foram executados. Furtado (2017) aponta que ainda que os programas para a área tenham sido previstos no planejamento estratégico, estes não se configuraram com uma prioridade da instituição na execução de suas ações.

Cabe questionar não apenas o aporte do orçamento destinado ao esporte educacional, mas a própria característica das competições escolares e universitárias nacionais, haja vista que a lógica do esporte de rendimento prevalece durante esses eventos, incluindo as competições de esporte adaptado (KIOURANIS, 2017). Além disso, nenhum projeto executado pelo CPB no período analisado buscou o desenvolvimento de atividades de esporte e lazer participativo, excluindo a parcela da população com deficiência fora da idade escolar.

\section{A ATUAÇÃO DO COMITÊ PARALÍMPICO BRASILEIRO: DIÁLOGOS COM O INTERESSE PÚBLICO}

O CPB está vinculado ao IPC e exerce sua finalidade estatutária de representação, coordenação e direção do movimento paralímpico no Brasil (COMITÊ PARALÍMPICO BRASILEIRO, 2011). Todavia, outras organizações locais, nacionais e internacionais exercem um papel significativo na oferta do esporte adaptado às pessoas com deficiência (MARQUES, 2016). Para este autor, o IPC e o CPB legitimam-se como as instituições máximas do segmento paralímpico a nível internacional e nacional, porém restringem-se ao universo restrito das modalidades do programa dos Jogos Paralímpicos. Assim, orientam as suas ações apenas àquelas pessoas que atendem aos critérios de classificação instituídos pelas federações internacionais de cada modalidade. 
Desde 26 dezembro 2012, o CPB é outorgado pelo Ministério da Justiça com a qualificação de OSCIP. A solicitação da qualificação junto ao Ministério da Justiça é voluntária (VIOLIN, 2006), no entanto, os objetivos sociais das entidades solicitantes devem estar vinculados a pelo menos uma das seguintes áreas: 1) assistência social, 2) cultura, 3) acesso gratuito à educação e à saúde , 4) meio ambiente, 5) voluntariado, 6) desenvolvimento econômico e social, 6) empregabilidade e geração de renda, 7) defesa dos direitos, 8) promoção da ética, da paz, da cidadania, dos direitos humanos, da democracia e de outros valores universais, 9) transporte e 10) ciência e inovação tecnológica (BRASIL, 1999).

O princípio da universalização dos serviços está atrelado aos eixos de intervenção supracitados. Assim, a atividade-fim de uma OSCIP deve refletir o amplo acesso aos bens e serviços prestados. Schier (2016) aponta as políticas sociais de apoio e promoção de grupos histórica, econômica e socialmente desfavorecidos e a limitação razoável na oferta de serviços como exceções plausíveis. No entanto, a autora acrescenta que as desigualdades de acesso entre integrantes de um mesmo grupo social estão em discordância com este princípio.

A delimitação de pré-requisitos para a qualificação de OSCIP está pautada na noção de interesse público. Dentre as diferentes interpretações do termo, destaca-se o papel do poder público na ordenação e indicação dos termos e conteúdos de políticas e ações voltadas para o bem comum, visando à limitação das iniciativas de interesse particular e privado (GABARDO; REZENDE, 2017). Isso justifica a contingência interpretativa que Cyrino (2016) expõe ao problematizar que o "interesse público" não apontará sempre para uma mesma direção. Para o autor, dentro das lógicas da política, a noção de interesse público se apresenta de maneiras distintas de acordo com os gestores públicos eleitos, a conjuntura socioeconômica envolvida, a ação dos grupos de oposição e dos movimentos sociais e outros aspectos. Ainda assim, interpretações extraordinárias precisam se adequar ao princípio da legalidade.

Em conjunto, o estatuto, o planejamento estratégico e os projetos financiados por meio de Termos de Parceria e via Lei Agnelo/Piva da instituição não elucidam alinhamento entre as especificidades do movimento paralímpico e o interesse público no que tange à oferta universal de serviços para a população com deficiência, sem predileção entre atletas e não atletas. Apesar do segundo eixo de atuação previsto no PE da organização prever a promoção da universalização do acesso das pessoas com deficiência à prática esportiva em suas diferentes manifestações, os objetivos institucionais descritos no estatuto do CPB reiteram os propósitos e as finalidades do IPC no tocante ao fomento do esporte de alto rendimento.

O terceiro setor é um campo de disputas e, dado o caráter simbiótico da relação com 0 setor público, o posicionamento estratégico para a captação de recursos públicos determina a sustentabilidade das organizações (LOPEZ; BARONE 2013). No caso do esporte paralímpico a relação torna-se basilar, considerando-se a dificuldade atrair patrocinadores (COTTINGHAM; GEARITY; BYON, 2013). As parcerias entre o Estado, por meio do Ministério do Esporte, e o CPB entre os anos de 2010 e 2015 totalizam R $\$ 75$ milhões ${ }^{12}$ em investimentos para 0 treinamento e competição de atletas e equipes de alto rendimento. Este valor soma-se quase $\mathrm{R} \$ 400$ milhões em investimentos adquiridos entre os anos de 2010 e 2016 via Lei Agnelo/Piva e a Lei Pelé.

A partir de 2012 o CPB pôde agregar outros $\mathrm{R} \$ 75$ milhões a suas receitas por meio de Termos de Parceria viabilizados pela qualificação como OSCIP. No entanto, os dados dos anos

12 Portal da Transparência. Disponível em: http://transparencia.gov.br/. Acesso em: 18 out. 2019. 
anteriores indicam que, mesmo antes da qualificação, a organização firmou contratos para 0 financiamento de projetos com verba pública. Assim, os dados não evidenciam se a solicitação de qualificação como OSCIP objetivou formalizar a relação com o poder público por meio dos Termos de Parceria ou o incremento das receitas da instituição. Enquanto OSCIP, o CPB se beneficia adquirindo a oportunidade de pleitear o financiamento público de projetos adicionais em adição aos recursos já assegurados pela Lei Agnelo/Piva.

A tentativa de vincular a atuação do CPB a uma perspectiva universalizante, inclusiva e empoderadora no cenário esportivo brasileiro é um sofismo. A execução de projetos do CPB entre 2010-2016 prioriza os interesses do IPC no que se refere à expansão e desenvolvimento do esporte paralímpico. Apesar do papel das ações desenvolvidas no tocante à valorização do atleta com deficiência, o IPC está no âmago do sistema esportivo mundial e coaduna com a lógica mercantil desse espaço privilegiado de atuação (ALLISON; TOMLINSON, 2017). Assim, o corolário do alinhamento institucional com o IPC é a priorização do desenvolvimento do esporte de elite, uma vez que este é o produto que mantém as atividades dessas organizações.

No caso do CPB, em conformidade com a legislação de financiamento esportivo, durante todo o período analisado há a intensificação do investimento do esporte competitivo em ações de interesse privado em detrimento da promoção de programas de acesso ao esporte e ao lazer escolar e comunitário. A Lei Agnelo/Piva, ao estabelecer que a obrigatoriedade mínima dos investimentos no esporte educacional (escolar e universitário) seja de apenas 15\% do total de recursos públicos advindos das loterias federais, viabiliza a ampla prevalência de projetos para o desenvolvimento do esporte de alto rendimento que é praxe nas organizações esportivas. Assim, verifica-se o ponto de incompatibilidade entre a legislação esportiva e a Lei das OSCIP.

Veronez (2005) observa que a Lei Agnelo/Piva contradiz as prioridades estabelecidas na Constituição Federal (CF), que prevê a priorização do esporte educacional (BRASIL, 1988). Castro e Souza (2015), analisando as propostas orçamentárias durante a preparação para os grandes eventos esportivos, identificaram que o orçamento durante o período analisado priorizou investimentos em infraestrutura e nos programas com foco no esporte de alto rendimento. Apesar da CF legitimar mudanças na dinâmica de financiamento em "casos específicos", a brecha jurídica fundamentou uma política de exceção que se estendeu durante toda a década do esporte no Brasil (2007-2016) e, dentro das prerrogativas da Lei Agnelo/Piva, torna-se ordinária.

Enquanto OSCIP, o CPB passa a competir por recursos ao lado de organizações do terceiro setor que atuam em áreas que não são contempladas por nenhuma política de repasse direto de recursos, como é o caso das organizações esportivas. Assim, a organização soma à vasta gama de direitos conferidos pela legislação esportiva brasileira o privilégio de pleitear a celebração de Termos de Parceria com maior agilidade, redução de despesas referentes a submissão de projetos, participação em editais públicos e busca por patrocínio privado (FERRAREZI, 2001b). Violin (2010, p. 277) alerta que o Estado, ao financiar OSCIP de forma indiscriminada, "abstém-se de fazer uma política social universal compulsória, não contributivista e gratuita", o que é evidenciado no caso do CPB.

É possível que a capitalização da receita anual milionária do CPB atinja os institutos, as associações e as iniciativas multissetoriais de caráter nacional, regional e local dedicadas à promoção dos direitos da pessoa com deficiência e/ou que desenvolvem projetos com foco 
na oferta de atividades de esporte e lazer adaptado. Porém, como apontam Lopez e Bueno (2012), as organizações locais carecem não apenas de capital simbólico para competir pelos recursos federais, como também de recursos humanos e materiais para a gestão e prestação de contas de recursos disponíveis pela legislação vigente.

No que tange às políticas de promoção dos direitos da pessoa com deficiência, 0 artigo 43 do Estatuto da Pessoa com Deficiência (BRASIL, 2015) estabelece que cabe ao poder público "[...] assegurar a participação da pessoa com deficiência em jogos e atividades recreativas, esportivas, de lazer, culturais e artísticas, inclusive no sistema escolar, em igualdade de condições com as demais pessoas". Assim, o financiamento público de atividades desenvolvidas pelo CPB por meio dos Termos de Parceria deveria anteferir projetos que ofertam atividades de esporte e lazer de caráter universal e inclusivo.

Por fim, no tocante ao interesse público, a Pesquisa Nacional por Amostra de Domicílios do ano de 2015, a maior consulta pública já realizada na área do esporte e atividade física no Brasil, aponta que 91,1\% (108 milhões) dos cidadãos brasileiros que concordam com 0 investimento público em atividades físicas ou esportivas defendem que o repasse de recursos seja para a promoção de atividades "para pessoas em geral" (IBGE, 2015, p.50). Apenas 8\% (9,5 milhões) do total da população consultada apoia o investimento na formação de atletas (IBGE, 2015).

Assim, a conjuntura na qual o CPB atua expõe pontos de conflitos entre as normativas próprias de diferentes sistemas legais, tornando os objetivos de fortalecimento de ações de interesse público desenvolvidas pela sociedade civil organizada da Lei das OSCIP ineficazes neste caso.

\section{CONSIDERAÇÕES FINAIS}

Este artigo buscou analisar os projetos de intervenção do CPB financiados com recursos públicos entre os anos de 2010 e 2016, confrontando-os a partir das especificações legais que definem a atuação das organizações de interesse público e das organizações esportivas.

A articulação entre o CPB e o governo federal se dá por meio do financiamento prescrito através de leis, convênios e, adicionalmente, por meio de termos de parcerias garantidos pelo reconhecimento da instituição enquanto OSCIP. As ações, projetos e o planejamento das atividades elaboradas pelo CPB são desenvolvidos de forma autônoma a partir de interesses privados. $O$ Estado atua na condição de gerencialista, fiscalizando a aplicação dos recursos via Tribunal de Contas da União. Os resultados aqui apresentados reforçam os apontamentos críticos de estudos sobre a atuação das OSCIP e das organizações esportivas.

Verificamos que o CPB tem como foco o desenvolvimento do esporte de alto rendimento, dedicando-se, portanto, a uma parcela seleta de atletas e às modalidades de esporte adaptado do programa paralímpico. Os projetos desenvolvidos pelo CPB no período não contribuem para a democratização do acesso ou ampliação da oferta ao esporte adaptado.

A própria legislação esportiva, por meio da Lei Agnelo/Piva, maior fonte de recursos da instituição, legitima a destinação massiva de recursos para o esporte de rendimento, ao fixar o percentual mínimo de repasse ao esporte educacional e universitário de 15\%. Esta legislação abre precedentes para as práticas escusas de organizações esportivas, especialmente em 
função da inexistência de percentuais mínimos de investimento no esporte de participação. Apesar do repasse majoritário ao esporte de alto rendimento se justificar pelas determinações da Lei Agnelo/Piva, os recursos advindos dos Termos de Parceria, celebrados em função da qualificação do CPB enquanto OSCIP, deveriam cumprir as determinações e condições da normativa. Ou seja, preconizar o uso de recursos públicos para a execução de serviços de caráter universalista. Há, portanto, incompatibilidades entre a Lei das OSCIP e a aplicação costumária da Lei Agnelo/Piva pelos comitês esportivos.

Os repasses públicos federais ao CPB no período de 2010 a 2016 totalizaram cerca de $\mathrm{R} \$ 530$ milhões e a organização se beneficiou da contradição das leis que regulamentam o financiamento esportivo no país, não desenvolvendo nenhum projeto de caráter abrangente e universal. Assim, o caso do CPB indica contradições da qualificação da instituição como OSCIP, dado que a organização já desfruta de repasse direto de verbas federais extraordinárias e atua com foco em projetos para o desenvolvimento do esporte de alto rendimento.

Longe de esgotar as problematizações acerca da atuação do CPB enquanto uma OSCIP no âmbito esportivo, este trabalho abre um campo profícuo de investigação sobre a atuação do CPB e de outras organizações esportivas do terceiro setor, especialmente no contexto das novas proposições do Marco Legal do Terceiro Setor (Lei nº 13.204/2015) (BRASIL, 2015). Entre as possíveis áreas de aprofundamento destacamos 1) a discrepância entre a expectativa popular e atuação do poder público em parceria com as grandes organizações do terceiro setor esportivo, 2) as estratégias de competição na captação recursos públicos entre diferentes organizações esportivas do terceiro setor, e 3) a caracterização da mudança organizacional das ONGs que desenvolvem programas e projetos esportivos com a partir da incorporação de princípios de Governança Corporativa.

\title{
REFERÊNCIAS
}

\author{
ALLISON, Lincoln. TOMLINSON, Alan. Understanding International Sport Organisations. \\ London: Routledge, 2017.
}

BOSSCHER, Verlee De. A Conceptual Framework for Analysing Sports Policy Factors Leading to International Sporting Success. European Sport Management Quarterly, v. 6, n. 2, p. 185215, 2006.

BOSSCHER, Verlee De et al. Explaining international sporting success: An international comparison of elite sport systems and policies in six countries. Sport Management Review, v. 12, n. 3, p. 113-136, 2009.

BRASIL. Constituição (1988). Constituição da República Federativa do Brasil. Senado Federal: Brasília, 2006. Disponível em: http://www.senado.gov.br/sf/legislacao/const/con1988/ CON1988 05.10.1988.pdf Acesso em: 04 jul. 2018.

BRASIL. Lei no 9.615 de 24 de março de 1998. Institui normas sobre desporto e dá outras providências. Diário Oficial da República Federativa do Brasil. Brasília DF, 25 mar. 1998. Disponível em: http://www.planalto.gov.br/ccivil 03/LEIS/L9615Compilada.htm. Acesso em: 15 mar. 2018. 
BRASIL. Lei no 9.790, de 24 de março de 1999. Dispõe sobre a qualificação de pessoas jurídicas de direito privado, sem fins lucrativos, como Organizações da Sociedade Civil de Interesse Público, institui e disciplina o Termo de Parceria, e dá outras providências. Disponível em: http://www.planalto.gov.br/ccivil 03/LEIS/L9790.htm. Acesso em 20 jul. 2018.

BRASIL. Decreto Lei oㅜ 10.264 de 16 de julho de 2001. Acrescenta inciso e parágrafos ao artigo 56 da lei 9.615, de 24 de março de 1998, que institui normas gerais sobre desporto. Diário Oficial da República Federativa do Brasil. Brasília DF, 17 jul. 2001. Disponível em: http://www. planalto.gov.br/ccivil_03/LEIS/LEIS_2001/L10264.htm Acesso em: 23 jan. 2018.

BRASIL. Esporte e Lazer: Políticas de Estado - Caderno 2: Construindo o Sistema Nacional de Esporte e Lazer. Brasília: Ministério do Esporte, 2009.

BRASIL. Lei 13.146 de 6 de julho de 2015. Estatuto da Pessoa Com Deficiência. Brasília: Senado Federal, 2015. Disponível em: https://www2.senado.leg.br/bdsf/bitstream/handle/ id/513623/001042393.pdf. Acesso em: 19 fev. 2018.

BUENO, Luciano. Políticas Públicas do esporte no Brasil: razões para o predomínio do alto rendimento. 2008. 314 f. Tese (Doutorado em Administração Pública e Governo) - Curso de Administração Pública e Governo, Escola de Administração de Empresas de São Paulo, Fundação Getúlio Vargas, São Paulo, 2008. Disponível em: <https://bibliotecadigital.fgv.br/dspace/ bitstream/handle/10438/2493/72040100444.pdf>. Acesso em: 27 out. 2019.

CARAVAGE, Andresa; OLIVER, Fátima Corrêa. Políticas públicas de esporte e lazer para pessoas com deficiência. Movimento, v. 24, n. 3, p. 987-1000, 2018.

CASTRO, Suélen Barboza Eiras de; SOUZA, Doralice Lange de. Os Jogos Olímpicos e Paralímpicos Rio 2016: propostas para o esporte educacional, de participação e de rendimento. Revista Brasileira de Educação Física e Esporte, v. 29, n. 3, p. 507-518, 2015.

COMITEE PARALÍMPICO BRASILEIRO. Brasil assina acordo de parceria com três países da América Latina. Rio de Janeiro, 2017. Disponível em: http://cpb.org.br/noticia/detalhe/1518/brasilassina-acordo-de-parceria-com-tres-paises-da-america-latina. Acesso em: 15 abr. 2019.

COMITÊ PARALÍMPICO BRASILEIRO. Estatuto Social. Comitê Paralímpico Brasileiro. Brasil, 2011.

COMITÊ PARALÍMPICO BRASILEIRO. Planejamento Estratégico 2010- 2016. Brasília, 2009. Disponível em: http://gestaorecursos.cpb.org.br/documentos/planejamento/PlanejamentoEstrategico-2010-2016.pdf. Acesso em: 27 out. 2019.

CORREIA, Juliane Cristine Alves. O financiamento público do $3^{0}$ setor nas políticas públicas de esporte e lazer. Revista Brasileira de Ciências do Esporte, v. 36, n. 2, p.667-681, 2014.

COTTINGHAM, Michael; GEARITY, Brian; BYON, Kevin. A Qualitative Examination of Disability Sport Executives' Perceptions of Sport Promotion and the Acquisition of Sponsors. Sport Marketing Quarterly, v. 22, n. 2, p. 92-100, 2013. Disponível em: http://search.ebscohost.com/ login. aspx?direct=true\&db=bth\&AN=88992067\&site=eds-live. Acesso em: 16 abr. 2019.

CYRINO, André Rodrigues. Como se fazem as leis? Democracia, grupos de interesse e controle de constitucionalidade. Revista Brasileira de Estudos Políticos, n. 113, p. 51-99, jul./dez. 2016.

DIAS, Maria Tereza Fonseca. Terceiro setor e Estado: legitimidade e regulação: por um novo marco jurídico. Belo Horizonte: Fórum, 2008. 
FERRAREZI, Elisabete. O Novo Marco Legal do Terceiro Setor no Brasil. 2001a. Disponível em: http://www.lasociedadcivil.org/wp-content/uploads/2014/11/ferrarezi.pdf Acesso em: 16 out. 2019.

FERRAREZI, Elisabete. OSCIP Organização da Sociedade Civil de Interesse Público: A Lei 9.790/99 como alternativa para o terceiro setor. 2. ed. Brasília: Comunidade Solidária, 2001b.

FERRAREZI, Elisabete; REZENDE, Valéria. OSCIP: organização da sociedade civil de interesse público: a lei 9.790/99 como alternativa para o terceiro setor. 3. ed. Brasília: Comunidade Solidária, 2005.

FIGUERÔA, Katiuscia Mello et al. Planejamento, ações e financiamento para o esporte em tempos de megaeventos. Motrivivência, v. 26, n. 42, p. 55-71, 2014.

FURTADO. Sabrina. As ações, os projetos e o financiamento do Comitê Paralímpico Brasileiro no período de 2010 a 2015. 2017. Dissertação (Mestrado em Educação Física) - Curso de Educação Física, Setor de Ciências Biológicas, Universidade Federal do Paraná, Curitiba, 2017.

GABARDO, Emerson; REZENDE, Maurício Corrêa de Moura. O conceito de interesse público no direito administrativo brasileiro. Revista Brasileira de Estudos Políticos, n. 115, p. 267-318, 2017.

GREEN, Mick; HOULIHAN, Barrie. Elite Sport Development: Policy Learning and Political Priorities. Abingdon: Routledge, 2005.

GREEN, Mike; OAKLEY, Ben. Elite sport development systems and playing to win: uniformity and diversity in international approaches. Leisure Studies, v. 20, n. 4, p. 247-267, 2001.

HADDAD, Sérgio et al. (org.). ONGs e Universidades: Desafios para a cooperação na América Latina. São Paulo: Peirópolis, 2002.

HALL, Peter Dobkin. Historical perspectives on Nonprofit Organization. In: RENZ, David; HERMAN, Robert. The Jossey-Bass Handbook of nonprofit leadership and management. San Francisco: Jossey-Bass, 1994. p.3-38.

HOULIHAN, Barrie; ZHENG, Jinming. The Olympics and Elite Sport Policy: Where Will It All End? The International Journal of the History of Sport, v. 30, n. 4, p. 338-355, 2013.

HOWARD, D. R.; CROMPTON, John L. Financing Sport. 4. ed. Morgantown: Fit, 2018.

IBGE - INSTITUTO BRASILEIRO DE GEOGRAFIA E ESTATÍSTICA. As fundações privadas e associações sem fins lucrativos no Brasil 2010. Rio de Janeiro, 2012.

IBGE - INSTITUTO BRASILEIRO DE GEOGRAFIA E ESTATÍSTICA. Pesquisa Nacional por Amostra de Domicílios: Práticas de esporte e atividade física. Brasília: IBGE, 2015. Disponível em: https://biblioteca.ibge.gov.br/visualizacao/livros/liv100364.pdf. Acesso em: 19 fev. 2019.

INTERNATIONAL PARALYMPIC COMMITTEE. Paralympic Vision Paralympic Mission. In: IPC Handbook. Bonn: International Paralympic Committee, 2003. p.1-3.

KIOURANIS, Taiza Daniela Seron. Os jogos escolares brasileiros chegam ao século XXI: reprodução ou modernização na política de esporte escolar? 2017. 294 f. Tese (Doutorado) - Curso de Educação Física, Setor de Ciências Biológicas, Universidade Federal do Paraná, Curitiba, 2017. 
KOGA, Natália Massaco. As Organizações da Sociedade Civil de Interesse Público (OSCIPS) e os Termos de Parceria: uma reflexão sobre a relação entre Estado e sociedade civil. 2004. 180 f. Dissertação (Mestrado em Administração Pública e Governo) - Escola de Administração de Empresas de São Paulo, Fundação Getúlio Vargas, São Paulo, 2004. Disponível em: http://hdl.handle.net/10438/2413. Acesso em: 21 out. 2019.

LAHOZ, Rodrigo Augusto Lazzari; DUARTE, Francisco Carlos. Saneamento básico e direito à saúde: considerações a partir do princípio da universalização dos serviços públicos. Revista de Estudos Constitucionais, Hermenêutica e Teoria do Direito (RECHTD), v. 7, n. 1, p.62-69, 2015.

LANDIM, Leilah. A invenção das ONGs: do serviço invisível à profissão impossível. 1996. 239 f. Tese (Doutorado em Antropologia Social) - Museu Nacional da Universidade Federal do Rio de Janeiro, Rio de Janeiro, 1996.

LEE, Younghan et al. A Qualitative Systematic Review of Public-Private Partnership in Promoting Physical Activity. Evaluation \& the Health Professions, p.1-34, 2018.. Disponível em: https://doi.org/10.1177/0163278718796153 Acesso em: 21 out. 2019.

LEGG, Eric; JONES, Gareth; WHITE, Misha. Whose job is it anyway? Public-private partnerships in youth sport. Managing Sport and Leisure, v. 23, n. 4-6, p.261-276, 9 out. 2018. Disponível em: http://dx.doi.org/10.1080/23750472.2018.1530070. Acesso em: 21 out. 2019.

LIMA NETO, Fernando. Relação com o Estado na visão das ONGs: uma sociologia das percepções. Brasília: IPEA, 2013. Disponível em: http://repositorio.ipea.gov.br/ bitstream/11058/912/1/td 1820.pdf. Acesso em: 21 out. 2019.

LINHALES, Meily Assbú. A Trajetória política do esporte no Brasil: interesses envolvidos, setores excluídos. 1996. 242 f. Dissertação (Mestrado em Ciência Política) - Faculdade de Filosofia e Ciências Humanas da Universidade Federal de Minas Gerais, Belo Horizonte, 1996.

LOPEZ, Felix; BARONE, Leonardo. As organizações da sociedade civil e as políticas federais (2003-2011). Boletim de Análise Institucional. Brasília: Ipea, 2013.

LOPEZ, Felix; BUENO, Natalia. Transferências federais a entidades privadas sem fins lucrativos (1999-2010). Rio de Janeiro: Ipea, 2012. Disponível em: http://www.ipea.gov.br/portal/ images/stories/PDFs/TDs/td 1778.pdf. Acesso em: 29 out. 2019.

MARQUES, Renato Francisco Rodrigues. A contribuição dos Jogos Paralímpicos para a promoção da inclusão social: o discurso midiático como um obstáculo. Revista USP, n. 108, p. 87-96, 2016.

MARQUES, Renato Francisco Rodrigues et al. Esporte olímpico e paraolímpico: coincidências, divergências e especificidades numa perspectiva contemporânea. Revista Brasileira de Educação Física e Esporte, v. 23, n. 4, p. 365-377, 2009.

MARQUES, Renato Francisco Rodrigues; GUTIERREZ, Gustavo Luis. O Esporte

Paralímpico no Brasil: profissionalismo administração e classificação de atletas. São Paulo: Phorte, 2014.

MELLO, Marco Túlio de; OLIVEIRA FILHO, Ciro Winckler. Esporte e a pessoa com deficiênciaContexto Histórico. In: MELLO, Marco Túlio de; OLIVEIRA FILHO, Ciro Winckler (eds.). Esporte Paralímpico. São Paulo: Atheneu, 2012. p. 254. 
MELO, Marcelo Paula de. O chamado terceiro setor entra em campo: políticas públicas de esporte no governo Lula e o aprofundamento do projeto neoliberal de terceira via. Licere, v. 10, n. 2, p. 1-35, 2007.

MELO, Marcelo Paula de. As ONGs de cultura e recreação no Brasil: Análise do censo IBGE IPEA 2005. In: CONGRESO ARGENTINO DE EDUCACIÓN FÍSICA Y CIENCIAS, 12., 2017, Enseada, Argentina. Anais [...]. Ensenada, Argentina: Universidad Nacional de La Plata. Facultad de Humanidades y Ciencias de la Educación. Departamento de Educación Física. Tema: Educación Física: construyendo nuevos espacios. Disponivel em: http://www.memoria. fahce.unlp.edu.ar/trab eventos/ev.10252/ev.10252.pdf. Acesso em: 06 ago. 2019.

MIRANDA, Tatiane Jacusiel. Comitê Paralímpico Brasileiro: 15 anos de história. 2011. 329f. Dissertação (Mestrado em Educação Física) - Universidade Estadual de Campinas, Faculdade de Educação Física, Campinas, SP. Disponível em: http://www.repositorio.unicamp.br/handle/ REPOSIP/275043. Acesso em: 29 out. 2019.

REIS, Rafael Estevam. Políticas públicas para o esporte paralímpico brasileiro. 2014. $121 f$. Dissertação (Mestrado em Educação Física) - Curso de Educação Física, Setor de Ciências Biológicas, Universidade Federal do Paraná, Curitiba, 2014.

ROCHA, Ivan Barreto de Lima; FEITOSA, Marcos Gilson Gomes. Governança em ONGs: um ensaio teórico. Cadernos de Gestão Social, v.4, n.1, p.25-37, 2013.

SCHIER, Adriana da Costa Ricardo. Serviço público: garantia fundamental e proibição de retrocesso social. Curitiba: Íthala, 2016.

SILVA, Otavio Guimaraes Tavares da.; ROMERA, Liana; BORGES, Carlos Nazareno. A sociologia pública no âmbito da produção e intervenção em esporte e lazer no Brasil. Movimento, v. 20, n. esp., p. 97-108, 2014.

THIESENA, Rafaela Dalabilia. A evolução do terceiro setor brasileiro e sua relação com o estado. Direito em Debate, v. 17, n. 31, p. 105-125, 2009.

TRINDADE, Nadyne Venturini. A "Caixa-Branca" dos Projetos Sociais Esportivos: O CASO DO INSTITUTO COMPARTILHAR - CURITIBA/PR. 2017. 204 f. Dissertação (Mestrado em Educação Física) Curso de Educação Física, Setor de Ciências Biológicas, Universidade Federal do Paraná, Curitiba, 2017.

VERONEZ, Luiz Fernando Camargo. Quando o Estado Joga a Favor do Privado: As políticas de esporte após a Constituição Federal de 1988. 2005. Tese (doutorado em Educação Física) Faculdade de Educação Física, Universidade Estadual de Campinas Universidade Estadual de Campinas, 2005.

VIOLIN, Tarso Cabral. Uma análise crítica do ideário do "terceiro setor" no contexto neoliberal e as parcerias entre a administração pública e sociedade civil organizada no Brasil. 2006. 241 f. Dissertação (Mestrado em Direito) - Faculdade de Direito, Universidade Federal do Paraná, Curitiba, 2006.

VIOLIN, Tarso Cabral. Terceiro setor e as parcerias com a Administração Pública: uma análise crítica. 2. ed. Belo Horizonte: Fórum, 2010. 


\section{Apoio:}

O presente trabalho foi realizado com apoio da Coordenação de Aperfeiçoamento de Pessoal de Nível Superior -Brasil (CAPES) - Código de Financiamento 001. This study was financed in part by the Coordenação de Aperfeiçoamento de Pessoal de Nível Superior - Brasil (CAPES). Finance Code 001". 